\title{
EXTROVERSÃO DO PATRIMÔNIO ARQUEOLÓGICO SALVAGUARDADO: RESERVA TÉCNICA DO LABORATÓRIO DE ARQUEOLOGIA PETER HILBERT
}

Daiane Pereira ${ }^{1}$

\section{RESUMO}

A limitação dos processos de extroversão das informações e dos bens arqueológicos é uma realidade corrente. Isso mantém as coleções maciçamente armazenadas, enquanto uma pequena parcela participa de exposições e ações educativas. Tendo como objeto de estudo a reserva técnica do Laboratório de Arqueologia Peter Hilbert, vinculada ao Instituto de Pesquisas Científicas e Tecnológicas do Estado do Amapá, a presente pesquisa analisa mecanismos conceituais e práticos que podem contribuir para a potencialização da reserva técnica desse núcleo de pesquisa em espaço de extroversão das informações e do patrimônio arqueológico. Ao problematizar as possibilidades e os desafios atuais da gestão das coleções arqueológicas salvaguardadas em reservas técnicas, abordo aspectos da cadeia operatória da museologia e da cadeia produtiva da arqueologia, utilizando como arcabouço teórico a relação interdisciplinar entre a arqueologia e a museologia, relativa ao processo de musealização do patrimônio arqueológico.

PALAVRAS-CHAVE: patrimônio arqueológico, reserva técnica, coleções, gestão, musealização.

\section{ABSTRACT}

The restriction of extraversion processes about information and archaeological goods is an actual reality. This keeps the archaeological collections massively stored, while a small portion of them participates in exhibitions and educational activities. Taking the storage room of the Peter Hilbert Laboratory of Archaeology as object of study, which is part of the Instituto de Pesquisas Científicas e Tecnológicas do Estado do Amapá, this research examines the conceptual and pratical mechanisms that may contribute to the enhancement of storage room of this research center as an place to spread of the information and archaeological heritage. To discuss the current possibilities and challenges of archaeological collections safeguard management in storage rooms, I discuss aspects of museological operation chain and of the productive chain of archeology, using as theoretical background the interdisciplinary relation between archaeology and museology on the process of the archaeological heritage musealization.

KEYWORDS: archaeological heritage, storage room, collections, management, musealization.

\section{RÉSUMÉ}

La limitation de la extraversion traite l'information et des biens archéologique est une realité

\footnotetext{
${ }^{1}$ Especialista em Patrimônio Arqueológico e Mestre em Arqueologia. É pesquisadora-colaboradora do Núcleo de Pesquisa Arqueológica do Instituto de Pesquisas Científicas e Tecnológicas do Estado do Amapá e arqueóloga na Peabiru Consultoria Arqueológica. E-mail: peabiruarqueologia@gmail.com.
}

\begin{tabular}{|l|c|c|c|c|c|c|}
\hline (C) Rev. Arqueologia Pública & Campinas, SP & v.11 & n.2 & p. 66 & Novembro/2017 & ISSN 2237-8294
\end{tabular}


des archeologes. Cette situation permet de maintenir les collections reteniées massivment, tandi qu'une petite parti participe à des exposition et des activités éducatives. Ayant comme objet d'étude la réserve technique du Laboratório de Arqueologia Peter Hilbert, unié au Instituto de Pesquisas Científicas e Tecnológicas do Estado do Amapá, cette recherche analyse les mécanismes conceptuel et pratique qui peuvent contribuer à l'amelioration de la réserve technique de ce seteur de la recherche pour la extraversion traite l'information et le patrimoine archeologique. Pour discuter des possibilites et les défis de la gestion des colletion archéologique protégés dans les réserves technique, je vous écris sur les aspects de la chaîne operatoire de la muséologie et de la chaîne de prodution de l'archéologie. Pour faire ça, J'utilize une cadre théorique comme la relation interdisciplinaire entre l'archéologie et la muséologie, sur le procés de muséalisation du patrimoin archéoplogique.

MOTS-CLÉS: patrimoine archéologique, réserve technique, colletions, gestion, muséalisation.

\section{INTRODUÇÃO}

O conceito de extroversão do patrimônio arqueológico está ligado à noção de expansão, comunicação, socialização, divulgação e publicização dos bens arqueológicos, tornando o conhecimento produzido pela arqueologia acessível para quem o almejar (BASTOS et al., 2007, p. 147). Com base nas discussões atuais sobre a gestão do patrimônio arqueológico e o papel da interdisciplinaridade entre a arqueologia e a museologia para as coleções salvaguardadas, busco problematizar a utilização da reserva técnica enquanto espaço e mecanismo de extroversão das informações e do patrimônio arqueológico.

O assunto é controverso, e, sem a pretensão de uniformizar posições, busco suscitar uma reflexão crítica sobre os espaços das reservas técnicas para coleções arqueológicas e suas práticas de reclusão do patrimônio. Embora sejam muitos os avanços ocorridos nos últimos anos, no que se refere à ampliação do acesso ao patrimônio arqueológico, é importante ressaltar que este patrimônio ainda é inacessível em boa parte e para razoável parcela da população. De modo geral, as instituições com objetos musealizados "não chegam ter nem $10 \%$ dos seus acervos acessíveis ao público" (MUSEÁLIA, 2010, p. 48), o que leva à indagação sobre a extroversão das informações dos outros $90 \%$ desses bens.

Sabe-se que, na maioria das vezes, apenas os artefatos de maior impressão visual são selecionados para exposições e publicações, enquanto os visualmente menos interessantes, como os vestígios fragmentados, por exemplo, são "escondidos" nas 
reservas técnicas, sem uma ponderação mais complexa do quão significativos podem ser para outros sentidos além dos aspectos visuais (CLASSEN; HOWES, 2006, p. 200).

É preciso ter cuidado, pois tal discurso tem uma tendência a pender perigosamente para a banalização da exposição dos objetos e para a projeção da extroversão para um modelo fixo de reserva técnica. Deve-se evitar a simplificação do conceito de extroversão aplicado às reservas técnicas apenas como ações de exposição e abertura, pois ela ultrapassa a metodologia de apresentação das coleções. Trata-se da problematização da estrutura da gestão das coleções arqueológicas no que diz respeito à limitação do acesso ao patrimônio salvaguardado e seu potencial social e informacional.

A extroversão alcança o espaço da reserva técnica quando busca uma diferenciação da concepção de patrimônio cultural e de suas funções. Varine-Bohan (2008, p. 14) referese a uma falsa percepção de mudança construída pelo anseio de apresentar uma "democratização cultural" que, em seu cerne, apresenta mudanças rasas de estrutura. De fato, muito se tem falado em democratizar o acesso ao patrimônio arqueológico, porém as estruturas restritivas mantêm-se como dogmas. A extroversão dos bens arqueológicos precisa ultrapassar o simples tornar disponível, precisa criar mecanismos que gerem mudanças profundas na forma como o patrimônio é percebido nas diferentes esferas da sociedade.

O patrimônio, como é percebido na atualidade, impõe ambiguidades que precisam ser superadas. Sobre a extroversão por meio da reserva técnica, impõe-se a questão de "preservar, evitando todo e qualquer risco de degradação, ou utilizar?" (SALADINO, 2009, p. 39). Algumas questões discutidas ao longo da consolidação das coleções foram sendo distorcidas e repetidas até se consolidarem como dilemas. Compartilho da visão de Maria Lucia Loureiro (2011, p. 7), que discute essas questões como falsos dilemas, ressaltando que a apresentação da salvaguarda e extroversão como características incomunicáveis é errônea por negligenciar uma gama de outras possibilidades; são falsas dicotomias: "objeto OU público, coleção OU comunidade". Um equilíbrio entre estes dois supostos elementos dicotômicos está sendo cada vez mais explorado.

De que maneira superar o engessamento dos modelos de como devem ser as reservas técnicas, possibilitando que novas perspectivas sejam construídas? Não há uma única resposta para a pergunta de como devem ser geridas e organizadas as reservas técnicas (TAPOL, 2012, p. 35). A pluralidade de contextos e coleções, assim como de objetivos estabelecidos pela gestão, resulta em uma série de possibilidades. Qualquer receita pronta de gestão das coleções arqueológicas seria ignorar essa pluralidade que, 
apesar de flexível, deve estar comprometida com os princípios fundamentais dos acervos: conservação, segurança, pesquisa, documentação e difusão.

Com isso, o intuito desta reflexão é unir-se aos demais elementos que compõem a gestão de coleções em reservas técnicas, trazendo uma discussão sobre as possibilidades e os desafios da extroversão do patrimônio arqueológico salvaguardado em reservas técnicas.

\section{RESERVAS TÉCNICAS: POSSIBILIDADES E DESAFIOS PARA A EXTROVERSÃO}

A origem do espaço da reserva técnica aconteceu, segundo Joana Amaral (2012, p. 2), quando se deixou os gabinetes de curiosidades para buscar apresentar o patrimônio de forma mais atrativa e para um público mais diversificado. Foi a necessidade de selecionar o que iria ser exposto que criou a demanda de uma quantidade maior de objetos, surgindo a reserva técnica como local de guarda.

Como herança do seu surgimento, a visão antagônica das funções das reservas e das exposições foi muito marcante na história das reservas técnicas. Todavia, exemplos bem sucedidos demonstram que uma das funções das reservas técnicas, assim como das exposições, é comunicar e possibilitar a extroversão das informações e do patrimônio arqueológico, tornando acessíveis os acervos que estão fora dos contextos expositivos.

Ao corroborar essa visão, Antonio Mirabile (2010, p. 05) delimita as funções das reservas técnicas associadas às exigências da conservação, facilitação do acesso e movimentação das coleções para pesquisas e difusão dos bens culturais.

As funções que as reservas desenvolvem estão diretamente ligadas à definição que Ihes é atribuída. No manual Museum Handbook, por exemplo, a reserva técnica é considerada um espaço, mas também um processo contínuo que atende à tarefa de proteger e organizar as coleções enquanto estão armazenadas (CUMBERLAND; FLORAY, 2012 , p. 7:1). Podemos associar este processo contínuo à gestão, que deve prever a extroversão desses acervos como parte fundamental do mesmo.

O pesquisador francês Luc Rémy (1999) reconhece a função das reservas técnicas na difusão das informações e do patrimônio. No seu artigo "Les réserves: stockage passif ou pôle de valorisation du patrimoine?" (em tradução livre: "As reservas: armazenamento passivo ou polo de valorização patrimonial?"), defende uma visão dinâmica dos patrimônios salvaguardados em reservas técnicas, ressaltando a necessidade de equilibrar as funções de conservação e difusão nesse espaço. Para Rémy (1999, p. 30), as reservas técnicas 
possuem cinco funções: serem funcionais, possibilitarem o acesso e a consulta ao patrimônio, ao mesmo tempo em que asseguram sua segurança e sua preservação. As cinco funções culminam na dupla missão de conservar e difundir o patrimônio.

Embora Rémy seja certeiro sobre a busca do equilíbrio das funções das reservas técnicas, todas as funções trazidas pelo autor compõem o amplo conceito de preservação. Dessa forma, percebe-se a preservação do patrimônio como o objetivo máximo da gestão das coleções salvaguardadas. Dentro desse conceito, estão todas as atividades pelas quais os objetos passam para que se tornem documentos, ou seja, a cadeia operatória museológica organizada pelos motes da salvaguarda (conservação, documentação, armazenamento) e comunicação (exposições, produção de material didático-pedagógico, divulgação científica, ação socioeducativa cultural) ${ }^{2}$. A reserva técnica, nesse processo, torna-se espaço, mas também mecanismo para as atividades/funções.

A compreensão de que a reserva técnica desempenha um importante papel na preservação do patrimônio é um dos motivos que vêm desencadeando uma atualização no seu conceito e incentivando distintos modelos de reserva, como: "reservas que permitem o acolhimento de acções de formação e investigação, reservas onde é possível ao público observar o trabalho de bastidores do museu, reservas livremente visitáveis, ou reservas onde decorrem outras acções de mediação e comunicação do museu" (AMARAL, 2012, p. 02).

A diversidade das reservas técnicas, suas características e funções devem ser condizentes com a amplitude do patrimônio e atribuições contemporâneas. Os caminhos da construção do conhecimento, cada vez mais participativos, corroboram para que as reservas técnicas saiam dos bastidores da arqueologia e assumam um papel protagonista na relação entre o público e o patrimônio arqueológico, garantindo o acesso às coleções sem colocar em risco sua conservação (AMARAL, 2012, p. 7).

Esses movimentos de mudança na concepção do espaço e das funções das reservas técnicas têm resultado na redefinição das reservas técnicas tradicionais e no surgimento de tipologias de reservas, como as reservas técnicas externas, compartilhadas, visitáveis e visíveis (DELAVENAYS, 2012, p. 10). A definição do perfil de cada uma deve partir de um plano de gestão adequado aos anseios da instituição e das coleções e comprometido com as funções de salvaguarda e comunicação. Não há um único modelo

\footnotetext{
${ }^{2}$ São seguidas aqui as subdivisões de salvaguarda e comunicação estabelecidas por Wichers (2011, p. 42).
} 
"certo" de reserva técnica, existem diferentes propostas e soluções para distintos projetos e objetivos.

Especificamente para a reserva técnica do Laboratório de Arqueologia Peter Hilbert, dois modelos de reservas foram priorizados como possibilidades, as reservas técnicas visitáveis e visíveis, por valorizarem a aproximação do público com as coleções em seus locais de guarda.

O que define uma reserva técnica como visitável não é somente seu acesso ao público, mas um conjunto de características que a configura como um espaço que consiga tornar as coleções salvaguardadas passíveis à construção de conhecimentos por parte do público em geral. A abertura pela abertura não modifica as visões sobre o patrimônio, pois é preciso criar um ambiente propício para essa função. Por isso, não existe reserva técnica visitável que desde sua criação não tenha sido pensada como espaço de apresentação, com as mesmas características de segurança, controle ambiental e iluminação de uma sala de exposição (TAPOL, 2012, p. 34).

Embora ainda pouco populares no Brasil, em outros países as reservas técnicas visitáveis e visíveis já constituem uma realidade consolidada. Reflexo dos debates das décadas de 1960 e 1970 sobre democratização das coleções, esses modelos de reservas surgiram para contrapor a inacessibilidade aos acervos, especialmente para respaldar a noção de que todos são detentores do patrimônio e como tal devem ter a ele acesso (ROMÃO, 2012, p. 94).

As discussões que esses modelos de reservas técnicas suscitam envolvem a dubiedade de suas características, de espaço privado e público. Nesse caso, deve-se buscar um equilíbrio entre as necessidades das coleções e as do público, tendo como fundamento que, antes de tudo, trata-se de um espaço de guarda e, em segundo plano, um espaço público (HIDALGO, 2012, p. 50). Um dos precursores deste conceito é Paul Thistle, para quem: "[...] visible storage is at one and the same time both a storage and a display system. Visitors need to be made aware that this is not the familiar type of thematic exhibit, and, particularly in light of the absence of structured orientation and programming" (THISTLE, 1997, p. 194).

O conceito e a intenção de uma reserva técnica visitável ou visível devem estar claros para seus gestores e também para o público visitante, para que este saiba diferenciar as peculiaridades do espaço e suas funções. Esse processo de diferenciação deve ocorrer também com os cuidados distintos que o espaço requer em termos de segurança, 
conservação, controle de acesso, espacialidade, mobiliário, sinalizações etc. (CARVALHAES, 2014, p. 47; DELAVENAYS, 2012, p. 11).

Visitas do público em geral às reservas técnicas são uma tendência atual, e mesmo as reservas que não possuem uma configuração de reserva técnica visitável têm organizado ações esporádicas de visitas guiadas. Sobre estas visitas programadas às reservas técnicas, Paloma García (2012, p. 28) aponta que este tipo de atividade deixou de ser inusitada, tornando-se uma prática cada vez mais comum, já que é possível controlar os riscos às coleções por meio da organização dos espaços e da vigilância de pontos vulneráveis. Porém, quando essas visitas ocorrem em caráter excepcional, não se considera como sendo uma reserva técnica visitável, e sim uma ação pontual de extroversão.

Há em construção um processo de valorização da reserva técnica ligado à superação de uma visão tradicional que percebe este espaço como um depósito sem ordem ou normas (DELAVENAYS, 2012, p. 9). A percepção estática atribuída anteriormente à preservação dos bens culturais, que isolava os objetos em nome de sua proteção física e jurídica, tem se modificado nas últimas décadas. Essa mudança ocorreu em grande parte pelos avanços dos conhecimentos acerca da conservação do objeto em seu ambiente e as discussões sobre uma maior acessibilidade a esses bens patrimoniais (MIRABILE, 2010, p. 04). Tal processo de revitalização tem auxiliado a consolidação das reservas técnicas enquanto elementos fundamentais para a gestão dos bens culturais, não somente pela guarda e pela conservação das coleções, mas pela intensificação do seu papel social por meio de seu contato com o público (DELAVENAYS, 2012, p. 8).

A modificação do posicionamento diante das reservas técnicas começa a refletir em diferentes ramos da pesquisa arqueológica. Cláudio Carlan destaca que as reservas técnicas "devem guardar seus acervos, não escondê-lo. Os objetos arqueológicos encarcerados nas reservas técnicas devem ser analisados, estudados e apresentados ao público acadêmico ou não" (CARLAN, 2012, p. 57).

A transformação da mentalidade associada aos acervos também é discutida por Gedley Braga (2003), que observa um movimento cada vez mais dinâmico associado às coleções, as quais perderam seu caráter estático e intocável, posição que tem contribuído para fomentar a discussão sobre o tema. De acordo com Garcia (2012), esta discussão não se restringe aos arqueólogos e gestores do patrimônio, mas também ocorre pela diligência da sociedade: 
La creciente demanda por parte de la sociedad y las administraciones públicas de accesibilidad a las colecciones de los museos, ha producido un cambio radical en la fisonomía de los almacenes de nuestros museos en las últimas décadas. De ser espacios casi inanimados han pasado a convertirse en lugares transitados diariamente por personal técnico y, con menos asiduidad, por personas ajenas a la institución (GARCíA, 2012, p. 25).

Não é apenas a visão de reserva técnica que tem se modificado, há também uma expansão das concepções sobre o patrimônio e da percepção do público visitante interessado pelas coleções arqueológicas. A identificação do perfil deste público visitante é importante, pois é por meio de sua interação com o patrimônio arqueológico salvaguardado que ocorre o processo de vivificação da reserva técnica.

A mudança no perfil do visitante, que deixa de ter um papel passivo às informações e passa a ser um ator ativo no processo de aproximação com o patrimônio, atribui a este novo ator a possibilidade de (re)criar discursos e percepções sobre o patrimônio (CURY, 2008 , p. 03). Segundo Varine-Bohan (2008, p. 11), mudanças no padrão de vida e na educação das sociedades desencadearam as mudanças no perfil do visitante que busca 0 patrimônio musealizado. O resultado mais latente é a expansão de público para diferentes setores sociais, o que explica não somente as mudanças de perfil, mas também o crescimento do interesse pelo patrimônio cultural. Embora essa discussão seja originária de estudos sobre o contexto expográfico, pode-se transpor tal análise para o contexto das reservas técnicas comprometidas com a extroversão das informações, refletindo sobre a oportunidade de o público (re)criar outras percepções sobre o patrimônio arqueológico.

Se a visão do público sobre o patrimônio arqueológico se modificou, o posicionamento das instituições com guarda de coleções arqueológicas musealizadas também. Dessa forma, as reservas técnicas como espaços de guarda precisam estar em sintonia com os benefícios públicos que as coleções necessitam suprir, o que atribui encontrar soluções que permitam às pessoas explorar as coleções para inspiração, aprendizagem e diversão (MERRIMAN, 2004, p. 89). No entanto, esse processo pode ser complexo para a disciplina arqueológica, que, além de possuir muitos desafios a serem aprimorados no que diz respeito à gestão das coleções salvaguardadas, precisa também superar as distâncias com o público, o que historicamente tem marcado sua trajetória enquanto ciência.

$\mathrm{Na}$ atualidade, as diretrizes da arqueologia expõem uma nova ênfase em relação ao papel do público; em vez de este estar a serviço da disciplina, tem se questionado o que a arqueologia pode fazer por ele (MERRIMAN, 2004, p. 89). Com isso, não se quer 
desconsiderar a essência da disciplina, ou todos os outros inúmeros caminhos de pesquisa, nem mesmo afirmar que a arqueologia só se justifica quando voltada à participação do público não arqueólogo. Porém, somente por meio do engajamento social é possível sair de um isolamento de pares e encontrar uma significância sólida e contínua na sociedade.

Para desempenhar efetivamente seu papel social, a arqueologia precisa atribuir às coleções salvaguardadas o protagonismo na relação entre o patrimônio e o público, já que elas representam a maior porcentagem de vestígios arqueológicos conhecidos. Tal situação só pode acontecer com a valorização das funções das reservas técnicas pelos próprios profissionais do patrimônio. Todos os arqueólogos trabalham direta ou indiretamente com as coleções, o que torna imprescindível a responsabilização destes profissionais com o processo de curadoria e gestão dos acervos (LIMA; RABELLO, 2007, p. 248).

A gestão adequada das coleções arqueológicas, que perpassa um amplo conjunto de ações, deve ser uma pauta permanente entre os pesquisadores do patrimônio arqueológico, tendo em vista a importância da sua preservação, inclusive para a continuidade de suas pesquisas. Já aos responsáveis pela gestão das reservas técnicas cabe fazer uma reflexão sobre o papel e a utilização desses espaços, configurando-os como locais de participação e trocas de conhecimentos tanto para agentes patrimoniais quanto para o público em geral (TAPOL, 2012, p. 33), sendo essencial responsabilizar e conferir incumbências a todos nesse processo de gestão.

\section{RESERVA TÉCNICA DO LABORATÓRIO DE ARQUEOLOGIA PETER HILBERT}

Ao reconhecer a importância da gestão dos acervos arqueológicos, o Núcleo de Pesquisa Arqueológica do Instituto de Pesquisas Científicas e Tecnológicas do Estado do Amapá (NuPArq/IEPA) cria o projeto de Curadoria Arqueológica para a reserva técnica do Laboratório de Arqueologia Peter Hilbert, iniciado em 2010. A princípio o projeto tinha como objetivo realizar a salvaguarda das coleções por meio da conservação, documentação e acondicionamento dos acervos.

Durante esse processo, o resultado dos estudos desenvolvidos direcionou o projeto para a necessidade de reflexão sobre a extroversão do patrimônio arqueológico salvaguardado (PEREIRA, 2012). Tal apontamento foi embasado pelas peculiaridades encontradas tanto na instituição quanto na comunidade, identificados em dois movimentos.

O primeiro movimento parte dos próprios gestores e membros do Núcleo de Pesquisa Arqueológica, que, desde a elaboração do projeto arquitetônico do prédio, com

\begin{tabular}{|l|l|l|l|l|l|l}
\hline (C) Rev. Arqueologia Pública & Campinas, SP & v.11 & n.2 & p. 74 & Novembro/2017 & ISSN 2237-8294
\end{tabular}


implementação da reserva técnica visível, concebem a reserva técnica como o coração do laboratório e preocupam-se tanto com as questões relativas à conservação das coleções quanto com aquelas que se referem à aproximação da comunidade com o patrimônio salvaguardado. Por configurar-se enquanto organismo de pesquisa, mas realizar todas as etapas de musealização dos objetos arqueológicos, o Núcleo identificou em seu plano curatorial a reserva técnica como um mecanismo importante na extroversão das coleções, tendo em vista seu espaço expográfico limitado e o anseio da comunidade em acessar acervos específicos. Dessa forma, concebeu-se a reserva técnica com a dupla missão de salvaguardar e comunicar suas coleções.

O segundo movimento surge da própria comunidade em geral, que busca uma maior aproximação com o patrimônio arqueológico salvaguardado. Embora existam espaços expográficos do patrimônio arqueológico amapaense, a constante procura da população pelo Laboratório de Arqueologia Peter Hilbert demonstra que esse público busca ultrapassar o acesso ao patrimônio para além dos espaços expositivos, apresentando uma demanda em conhecer como e onde ocorrem a pesquisa e a guarda dos vestígios arqueológicos.

Esses dois movimentos ocorrem em um contexto onde o patrimônio arqueológico está presente no cotidiano das pessoas devido à região possuir um alto potencial arqueológico. Não são raras as vezes que a procura pela coleção arqueológica tem um interesse pessoal, uma busca relacionada aos vestígios de uma determinada localidade ou sítio que represente um sentimento de pertença para público.

A partir desse cenário, a pesquisa parte do pressuposto de que a extroversão das informações e do patrimônio arqueológico no contexto das reservas técnicas pode auxiliar a ampliação do sentimento de pertença e a participação da sociedade nas questões que envolvem o patrimônio, pois oferece outra opção de significação das coleções. Ao buscar tornar acessível um ambiente normalmente restritivo, a extroversão da reserva técnica e das coleções ali salvaguardadas auxilia a problematizar os limites dos processos de comunicação dos bens arqueológicos e a sua aproximação com o público em geral. A especificidade do contato com as coleções arqueológicas em seus locais de salvaguarda não só possibilita um maior acesso ao patrimônio arqueológico como também auxilia a divulgação e a compreensão dos processos de preservação do patrimônio e das etapas da pesquisa arqueológica.

Em um processo contínuo de reconhecimento de desafios e busca para superá-los, a gestão das coleções salvaguardadas do Laboratório de Arqueologia Peter Hilbert iniciou um processo propositivo com algumas ações de extroversão ligadas à reserva técnica, 
diante dos elementos que indicavam uma demanda da comunidade por se aproximar das coleções sob sua guarda. São elas:

Visitas guiadas: as visitas guiadas são a maneira mais tradicional adotada por instituições culturais e, normalmente, caracterizam-se "pela formação de um grupo que é levado por um guia ou monitor que transmite informações por ele mesmo selecionadas sobre determinados objetos ou ideias contidas na exposição" (ALENCAR, 1989, p. 59). Esse tipo de ação deixa o visitante passivo às informações, restringindo sua participação na absorção de conhecimentos selecionados para ele. Com o objetivo de ressignificar a estrutura passiva das visitas guiadas, a partir de 2011 iniciou-se um programa de visitação ao Laboratório de Arqueologia Peter Hilbert que incluía sua reserva técnica visível como um dos aspectos utilizados.

As visitas guiadas buscam comunicar os espaços, as pesquisas e as coleções do laboratório, porém permitindo que o público possa contribuir na construção de conhecimentos e significados. As visitas não seguem um roteiro fixo e se adéquam conforme o público. A reserva técnica faz parte da visita de forma variada, às vezes pela observação através das paredes panorâmicas, outras pela própria visitação do seu espaço interno.

Embora ainda haja um caminho de aperfeiçoamento de metodologias e, especialmente no que se refere a um quadro profissional permanente e com exclusividade para desenvolver esse acolhimento dos visitantes, a avaliação é positiva, pois tem dado voz à comunidade e traz um feedback do trabalho realizado pelo Núcleo de Pesquisa Arqueológica do IEPA. Segundo a coordenadora do NuPArq, a experiência com o programa de visitações "tem oferecido um grande aprendizado para a equipe do laboratório no que tange à transmissão do conhecimento produzido e nossa capacidade de perceber interesses de públicos diversos na arqueologia" (CABRAL, 2014, p. 73).

Reserva técnica visível: o principal mecanismo de extroversão das coleções salvaguardadas no Laboratório de Arqueologia Peter Hilbert é a característica de sua reserva técnica ser visível. Através de paredes panorâmicas que funcionam como grandes vitrines para o interior da reserva técnica, o visitante consegue entrar em contato com boa parte das coleções sem precisar entrar em seu espaço físico. Esta é uma solução para equilibrar os desafios do acesso físico à reserva técnica. Ao observar as coleções no seu local de guarda, as reações do público visitante diferem das expressas no espaço de exposição. As respostas mais comuns dos visitantes são a perplexidade pela quantidade de materiais na reserva técnica e o interesse sobre o processo de curadoria dos materiais, 
como são armazenados, conservados, identificados etc. Tem-se observado que esses questionamentos são menos comuns na sala de exposição, quando as perguntas ficam mais focadas nas peças expostas, enquanto o contato com a reserva técnica faz com que os questionamentos se ampliem para o conjunto dos vestígios, tipos de vestígios etc.

O contato com a reserva técnica e suas coleções, mesmo que através dos vidros, tem auxiliado a compreensão não somente do processo de salvaguarda das coleções, mas também das etapas da pesquisa arqueológica. Pela observação das diferentes coleções, materiais e quantidades, os desafios de preservação e as responsabilidades que a instituição possui ao ser fiel depositária se tornam mais palpáveis aos visitantes, que, por vezes, demonstram empatia pelo trabalho desenvolvido.

Reserva técnica visitável: embora a reserva técnica do Laboratório de Arqueologia Peter Hilbert não se configure como uma reserva técnica visitável, pois não possui as características físicas para desenvolver tal função permanentemente, a depender dos objetivos estabelecidos na visita, em alguns casos a reserva técnica recebe visitantes em sua estrutura interna. Ainda não existe uma norma que estabeleça quais são esses casos, contudo, é utilizado o bom senso, pesando o número de visitantes e os objetivos por trás da visita. Tal categoria de visita normalmente ocorre quando há uma procura por uma peça específica, uma comunidade que vem "reencontrar" determinada coleção, pesquisadores que vêm conhecer a instituição ou a chegada de comunidades tradicionais, como grupos indígenas do estado.

Ações pontuais: algumas ações pontuais de extroversão das coleções arqueológicas salvaguardadas têm sido realizadas de forma esporádica. A experimentação de novas ações de extroversão também é extremamente importante para encontrar modelos mais eficazes para determinados públicos e situações, além de ampliar as possibilidades de significação das coleções pelo público. Quando não há possibilidade de visitação à reserva técnica e ao Laboratório de Arqueologia Peter Hilbert, uma das soluções que se encontrou foi levar parte das coleções até a comunidade ou grupo interessado. Essa aproximação tem ocorrido tanto em ações socioeducacionais quanto por meio de exposições temporárias em que o público pode ter acesso às peças das coleções.

Diferentes ações de extroversão do patrimônio salvaguardado e suas informações continuam sendo experimentadas no Laboratório de Arqueologia Peter Hilbert com o objetivo de expandir as formas de percepção do patrimônio arqueológico. A diversidade dessas ações, não somente com propostas distintas, mas com públicos diversificados, amplia as possibilidades de significação das coleções salvaguardadas e do sentimento de

\begin{tabular}{|l|l|l|l|l|l|l}
\hline (C) Rev. Arqueologia Pública & Campinas, SP & v.11 & n.2 & p. 77 & Novembro/2017 & ISSN 2237-8294
\end{tabular}


pertença do patrimônio na comunidade amapaense. Esse esforço em pautar outras formas de comunicar o patrimônio impõe a superação de desafios para garantir que as ações estejam em equilíbrio com a conservação das coleções.

\section{INDICATIVOS}

Os anseios atuais ligados ao patrimônio cultural e arqueológico impõem uma revisitação dos modelos de reservas técnicas para coleções arqueológicas, transformando estes espaços em importantes mecanismos de gestão, com funções cada vez mais protagonistas (DELAVENAYS; GRUSS, s/d, p. 42). Nesse sentido, o espaço da reserva técnica enquanto mecanismo de extroversão das informações e do patrimônio arqueológico é um posicionamento de resposta à demanda de ampliação do acesso ao patrimônio e suas informações.

Essa ampliação da abrangência das coleções e do patrimônio na sociedade é uma tendência atual e precisa ser atendida em diferentes frentes de atuação do patrimônio cultural. Cristina Bruno ressalta a necessidade de comprometimento em identificar novos caminhos de significação das coleções e anseios contemporâneos da sociedade, bem como aplicar "procedimentos museológicos de salvaguarda e de comunicação aliados às noções de preservação, extroversão e educação" (BRUNO, 2008, p. 25). A extroversão das informações e do patrimônio arqueológico por meio da reserva técnica encaixa-se nessas novas possibilidades de significação das coleções.

Reafirmando a importância das reservas técnicas nesses processos, Carlos Costa (2008) aponta para a demanda do objeto arqueológico por "espaços adequados a sua reinserção social, seja para seu tratamento, registro, análise, salvaguarda ou comunicação". As reservas técnicas possuem as características necessárias para atender essa demanda das coleções arqueológicas, justamente por poderem compor o processo de musealização do patrimônio arqueológico, que é um encontro interdisciplinar entre a arqueologia e a museologia, com os esforços de ambas em tornar mais acessíveis os bens patrimoniais.

Novas possibilidades acerca da extroversão das informações das coleções arqueológicas salvaguardadas são possíveis, se for assumido o desafio de ultrapassar as práticas e visões já enraizadas nas ações e nos discursos ligados à gestão do patrimônio. $\mathrm{Na}$ atualidade, com os avanços teóricos das diferentes disciplinas que compõem a gestão do patrimônio salvaguardado, é possível garantir que a conservação e extroversão das coleções caminhem juntas, sem conflitos. 
Dessa forma, a extroversão do patrimônio arqueológico salvaguardado vem somarse a outras ações das instituições patrimoniais, com o intuito de ampliar o acesso da população a esses bens. A escolha pelas ações a serem desenvolvidas na reserva técnica como forma de extroversão deve ser planejada conforme as características de cada caso e com os objetivos da instituição. As reservas técnicas não precisam ser visíveis ou visitáveis, e as instituições podem criar suas próprias ações de extroversão. A escolha e a criação de uma metodologia de extroversão devem respeitar as características das coleções e também de seus públicos, buscando adequarem-se à proposta da instituição.

A partir da experiência desenvolvida no Laboratório de Arqueologia Peter Hilbert, a extroversão das coleções arqueológicas a partir de ações na reserva técnica tem potencial para: a) aproximar o público em geral da realidade das coleções arqueológicas locais; b) possibilitar a compreensão das etapas de pesquisa arqueológica; c) ampliar o acesso às coleções arqueológicas e, assim, a novas possibilidades de significação do patrimônio arqueológico; d) suscitar o sentimento de pertença sobre o patrimônio arqueológico; e) expandir a percepção sobre o patrimônio arqueológico, diminuindo o papel passivo do público visitante; f) ampliar a participação da população nas tomadas de decisões ligadas ao patrimônio arqueológico local; g) dinamizar as ações de salvaguarda a partir do acompanhamento externo das próprias pelo público visitante; h) aumentar o público interessado em conhecer as coleções, tanto especialistas quanto público em geral; i) diversificar formas de apresentar e interagir com as coleções salvaguardadas; j) incentivar a empatia da população com o trabalho desenvolvido pela instituição e pela disciplina arqueológica e k) promover o reconhecimento da importância do espaço da reserva técnica na preservação do patrimônio arqueológico.

$\mathrm{O}$ acesso às coleções salvaguardadas pode ajudar também em novas formas de pensar as coleções. A extroversão das informações e dos patrimônios arqueológicos salvaguardados em reservas técnicas justifica-se na concepção de gestão compartilhada do patrimônio arqueológico, com a ampla participação da população nas tomadas de decisões ligadas ao patrimônio.

Toda ampliação no processo de extroversão do patrimônio é extremamente profícua, pois reconhece a importância social das pesquisas e dos bens patrimoniais a longo prazo e de modo contínuo e não apenas pontual. As reservas técnicas são mais um mecanismo a se somar nesse processo.

Os argumentos trazidos para esta discussão buscam refletir sobre a relação da sociedade com o patrimônio arqueológico salvaguardado e como o seu local de guarda 


\section{Revista de Arqueologia Pública}

pode tornar-se um importante mecanismo na preservação do patrimônio. Este é um assunto distante de se esgotar, e esta reflexão, em sua brevidade, traz a singela contribuição para apontar a necessidade de se desenvolver mais estudos nesta temática, possibilitando um aperfeiçoamento teórico e metodológico, mas, acima de tudo, uma expansão da aplicabilidade da extroversão a partir das reservas técnicas no contexto brasileiro.

\section{REFERÊNCIAS BIBLIOGRÁFICAS}

AMARAL, J. R.. Gestão de acervos em reservas técnicas. Informação ICOM. PT, Série II, n. 15, p. 2-9, 2012. Disponível em: <http://www.icom-ortugal.org/multimedia/info\%20ll15_dez11-fev12.pdf>. Acesso em: 08 dez. 2016.

ALENCAR, V. Museu: Se faz caminho ao andar. Cadernos Museológicos. Rio de Janeiro: Instituto Brasileiro do Patrimônio Cultural. n 1-2, p. 55-64. 1989.

BASTOS, R. L; SOARES, F. C; BRUHNS. A arqueologia na ótica institucional: IPHAN, contrato e sociedade. Erechim: Ed Habilis. 200p. 2007.

BRAGA, G. D. Conservação Preventiva: acondicionamento e armazenamento de acervos complexos em Reserva Técnica - o caso do MAE/USP. Dissertação (Mestrado), Programa de Pós-Graduação em Arqueologia, MAE/USP. 2003.

BRUNO, M. C. O. Museus, identidades e patrimônio cultural. Revista do Museu de Arqueologia e Etnologia, Suplemento 7, p.145-151, 2008.

CABRAL, M. P. No tempo das pedras moles: arqueologia e simetria na floresta. Tese (Doutorado) - Universidade Federal do Pará, Instituto de Filosofia e Ciências Humanas, Programa de Pós-Graduação em Antropologia, Belém, 262p. 2014.

CARLAN, C. U. Arqueologia e Patrimônio: os acervos dos museus e sua importância. Arqueologia Pública, Campinas, n. 5, p. 56-63, 2012.

CARVALHES, R. S. Museu Dom João VI: uma reserva técnica acessível. Monografia (Especialização), Pós-Graduação lato sensu em Acessibilidade Cultural. Rio de Janeiro: Universidade Federal do Rio de Janeiro. 75p. 2014.

CLASSEN, C.; HOWES, D. Howes. The Museum as Sensescape: western sensibilities and Indigenous artifacts. In: EDWARDS, E.; GOSDEN, C.; PHILLIPS, R. B. (Eds), Sensible Objects: colonialism, museums and material culture. New York: Berg, p. 199-222. 2006.

COSTA, C. A. S. Museologia e Arqueologia - parte 1: a materialidade de uma relação interdisciplinar. Revista Museu, v. 40, p. 6, 2008. 
CUMBERLAND, D; FLORAY, S. Museum Handbook: Museum Collection Storage. Washington: National Park Service. Museum Management Program, 48p. 2012.

CURY, M. X. Novas Perspectivas para a comunicação museológica e os desafios da pesquisa de recepção em museus. Actas do I Seminário de Investigação em Museologia dos Países de Língua Portuguesa e Espanhola. p. 269-279. 2008.

DELAVENAY, A. H. De almacén acentro de conservación de colecciones. Revista del Comité Español del ICOM. ALMACENES DE MUSEOS: Espacios Internos Propuestas para su organización, ICOM España, v.3, p. 8-15, 2012.

DELAVENAYS, A. H.; GRUSS, C. R. Una visión del panorama internacional. Revista del Comité Español del ICOM, n. 4. Colecciones en Depósito: Experiencias en reservas nacionales e internacinales. p. 36- 42, s/d.

GARCÍA, P. M.C. Espacios para el tratamiento y conservación de las coleciones. Revista del Comité Español del ICOM. ALMACENES DE MUSEOS: Espacios Internos Propuestas para su organización, ICOM España, n. 3, p. 24-31, 2012.

HIDALGO, E. Aplicación del plan de emergencias para coleciones en el almacén. Revista del Comité Español del ICOM. ALMACENES DE MUSEOS: Espacios Internos Propuestas para su organización, ICOM España, n. 3, p. 46-53, 2012.

LIMA, T. A.; RABELLO, A. M. C. Coleções arqueológicas em perigo. O caso do Museu Nacional da Quinta da Boa Vista. Revista do Patrimônio Histórico e Artístico Nacional/Patrimônio Arqueológico: o desafio da preservação, n. 33. p. 245-273, 2007.

LOUREIRO, M. L. N. M. Preservação in situ X ex situ: reflexões sobre um falso dilema. In: Seminario Iberoamericano de Investigación em Museologia, 3. Madrid, p. 1-10. 2011.

MERRIMAN, N. Involving the public in museum archaeology. In: Public Archaeology. Londres. Routledge, p. 85-108. 2004.

MIRABILE, A. A Reserva Técnica também é um museu. Boletim Eletrônico da ABRACOR, n. 1, p. 4-9, 2010.

MUSEÁLIA. Reserva Técnica Viva: Como alguns museus estão mudando a relação entre suas reservas técnicas e o público. Museália, revista de cultura e museus, Instituto Brasileiro de Museus, n. 1, Ano 1, 2010.

PEREIRA, D. Perspectivas da Curadoria Arqueológica: O caso do Laboratório de Arqueologia Peter Hilbert. Monografia de Especialização em Patrimônio Arqueológico da Amazônia. Macapá: Universidade do Estado do Amapá. 84p. 2012.

RÉMY, L. Les reserves: stockage passif ou pôle de valorisation du patrimoine? La Lettre de l'OCIM, n.65, p. 27-35, 1999. 
ROMÃO, A. A reserva visitável do Laboratorio Chimico (MCUL): Uma realidade em evolução. Asensio, Semedo, Souza, Asenjo \& Castro (Eds.) Series Iberoamericanas de Museología, v. 5, p. 93-101, 2012.

SALADINO, A. Arqueologia Patrimonializada e desenvolvimento social: perspectivas no Brasil e Portugal. Revista Eletrônica do Programa de Pós-Graduação em Museologia e Patrimônio, - PPG-PMUS Unirio | MAST - v.2, n.2, p.38-45, 2009. Disponível em: http://revistamuseologiaepatrimonio.mast.br/index.php/ppgpmus/article/viewFile/58/72 Acesso em: 10 de abril 2017.

TAPOL, B. D. La gestión de las colecciones en las áreas de reserva: missión, uso, agrupación de los fondos, mantenimient. Revista del Comité Español del ICOM. ALMACENES DE MUSEOS: Espacios Internos Propuestas para su organización, ICOM España, v. 3, p. 32-28, 2012.

THISTLE, P. Visible storage for the small museum. In: KNELL, S. (ed.) Care of collections. London: Routledge, p. 207-217. 1997.

VARINE-BOHAN, Hugues de. Museus e Desenvolvimento Social: um balanço crítico. In: BRUNO, Maria Cristina Oliveira; NEVES, Kátia Regina Felipini (coord). Museus como agentes de mudança social e desenvolvimento: propostas e reflexões museológicas. São Cristovão: Museu de Arqueologia de Xingó. p. 11-20. 2008.

WICHERS, C. A. M. Patrimônio Arqueológico Paulista: proposições e provocações museológicas. Tese (Doutorado), Programa de Pós-Graduação em Arqueologia, Universidade de São Paulo. 349p. 2011. 